\title{
Acute and chronic glycemic effects of aerobic training in patients with type 2 diabetes
}

\author{
Efeitos glicêmicos agudos e crônicos do treinamento aeróbio em pacientes \\ com diabetes tipo 2
}

\begin{abstract}
AUTHOR'S
Rodrigo Sudatti Delevatti ${ }^{1}$ (D)

Nathalie Netto $^{2}$ (D)

Isabel Heberle ${ }^{1}$ (D)

Cláudia Gomes Bracht ${ }^{2}$ (D)

Éder Santiago ${ }^{2}$ (D)

Salime Donida Chedid Lisboa² (D)

Rochelle Rocha Costa ${ }^{2}$ (D)

Alexandra Hübner ${ }^{3}$ (D)

Marco Fossati ${ }^{3}$ (D)

Luiz Fernando Martins Kruel ${ }^{2}$ (D)

1 Universidade Federal de Santa Catarina, Departamento de Educação Física, Florianópolis, Santa Catarina, Brasil.

2 Universidade Federal do Rio Grande do Sul, Departamento de Educação Física, Porto Alegre, Rio Grande do Sul, Brasil.

3 Hospitalar - Atenção Total à Saúde, Porto Alegre, Rio Grande do Sul, Brasil.
\end{abstract}

\section{CORRESPONDING}

Rodrigo Sudatti Delevatti rsdrodrigo@hotmail.com

Rua Deputado Antônio Edu Vieira, Prédio Administrativo do Centro de Desportos, sala 215, Universidade Federal de Santa Catarina, Florianópolis, Santa Catarina, Brazil.

CEP: 88040-900.

\section{DOI}

\section{$10.12820 /$ rbafs.23e0063}

\section{(cc) BY-NC-SA}

This work is licensed under the Creative Commons Attribution-NonCommercial-ShareAlike 4.0 International License.

\begin{abstract}
The aim of the present study was to analyze acute glycemic effects in different moments of an aerobic training, as well as to analyze the chronic effect of training, in patients with type 2 diabetes mellitus (T2D). The participants performed 16 weeks of interval aerobic training with three weekly sessions. The main part of each session consisted of nine blocks of five minutes, in which four minutes consisted of stimulus between $85 \%$ and $95 \%$ of the anaerobic threshold heart rate (ATHR) and one minute consisted of recovery below $85 \%$ of the ATHR, totalizing 45 minutes. Capillary glucose was assessed before, immediately after and 30 minutes after the first and the last training sessions. Glycated hemoglobin $(\mathrm{HbA} 1 \mathrm{c})$ was assessed before and after the intervention. Paired t-test and Generalized Estimating Equations were performed for the analyses; $\alpha=5 \%$. The participants were seven individuals (four women) aged $59.60 \pm 6.69$ years. In the first session, glucose values immediately after and 30 minutes after exercise were lower than pre-exercise values. On the other hand, in the last training session, only the glucose values immediately after exercise were lower than pre-exercise values. Analyzing the glycemic reductions, the first session presented a greater reduction immediately after $(\mathrm{p}=$ $0.042)$ and 30 minutes after exercise $(p=0.010)$. Regarding chronic glycemic effects, an increase ( $p$ $=0.010)$ in HbA1c levels was observed after training. It is concluded that, after 16 weeks of training without progression of duration and intensity, the exercise loses its acute glycemic effect, and may be even insufficient to reduce $\mathrm{HbA1c}$ levels.
\end{abstract}

Keywords: Diabetes mellitus; Glucose; Exercise; Physical activity.

\section{RESUMO}

O objetivo do estudo foi analisar os efeitos glicêmicos agudos em diferentes momentos de um treinamento aeróbio, bem como o efeito glicêmico crônico deste treinamento, em pacientes com diabetes tipo 2 (DM2). Os participantes realizaram16 semanas de treinamento aeróbio intervalado, com três sessöes semanais, sendo a parte principal de cada sessão composta de nove blocos de cinco minutos, tendo cada bloco quatro minutos de estímulo a $85 \%$ a $90 \%$ da frequência cardíaca referente ao limiar anaeróbio $\left(F C_{L A N}\right)$ e um minuto de recuperação abaixo de $85 \%$ da $F C_{L A N,}$ totalizando 45 minutos. A glicemia capilar foi avaliada antes, imediatamente e 30 minutos após a primeira e a última sessão de treinamento. A hemoglobina glicada (HbA1c) foi avaliada antes e após a intervenção. Teste t pareado e Equaçōes de Estimativas Generalizadas foram usados para as análises; $\alpha=5 \%$. Participaram sete individuos (59,60 $\pm 6,69$ anos; quatro mulheres). Na primeira sessão, os valores glicêmicos imediatamente e 30 minutos após o exercício foram menores que os valores pré-exercício. Já na última sessão de treinamento, somente os valores glicêmicos imediatamente após o exercício foram menores que os valores pré-exercício. Analisando as reduçōes glicêmicas, a primeira sessão apresentou maior redução tanto imediatamente após $(p=0,042)$ como 30 minutos após o exercício $(p=0,027)$. Em relação ao efeito glicêmico crônico, observou-se aumento $(p=0,010)$ dos niveis de HbA1c após o treinamento. Conclui-se que após 16 semanas de treinamento sem progressão de duração e intensidade, o exercício perde efeito glicêmico agudo, podendo inclusive ser ineficiente na redução dos niveis de HbA1c.

Palavras-chave: Diabetes mellitus; Glicemia; Exercício; Atividade física.

\section{Introduction}

Type 2 diabetes (T2D) is a chronic noncommunicable disease originating, among other factors, in sedentary lifestyles and poor eating habits. It is mainly characterized by persistent hyperglycemia ${ }^{1}$. Due to the damage caused by this condition, the primary outcome in the treatment of T2D is glycemic control. One of the therapeutic treatments indicated for glycemic control is the practice of physical exercise, especially aerobic training $^{1,2}$. Although the American Diabetes Association $(\mathrm{ADA})^{1}$ also recommends strength exercises for people with T2D, they have a complementary nature, as the 
priority is aerobic training performed at least three times per week, with moderate to vigorous intensity, and weekly duration preferably around 150 minutes $^{1}$.

Regarding the acute effect of exercise, studies with different aerobic training protocols have been showing glycemic reductions ${ }^{3-6}$. However, these studies usually analyze the response of different sessions in the same training status, without investigating the acute glycemic effects throughout the exercise programs. Following the opposite direction, Delevatti et al. ${ }^{7}$ assessed the acute glycemic response throughout an aerobic training program with progression in intensity and found the same magnitude of reduction during 12 weeks of intervention.

As for the chronic effect of exercise on glycated hemoglobin (HbA1c) levels, sometimes, protocols of isolated aerobic training are not effective ${ }^{8-10}$. Analyzing the training structure in these studies critically, it is possible to notice the use of fixed doses of volume and intensity, that is, no progression in the physiological/ internal load during the interventions. On the other hand, studies ${ }^{7,11}$ in which there is progression of volume and/or intensity throughout the training usually find reductions in $\mathrm{HbA1c}$ levels, even with exercise prescriptions that differ from the recommendations. Therefore, progression of the training variables - in volume, intensity or both - can be an important factor to obtain chronic glycemic effects, as the chronic effects of fixed exercise doses can be negatively influenced by the loss of the acute impact over time.

Thus, investigating acute glycemic effects at different moments of an aerobic training protocol, associated with the analysis of the chronic glycemic response of this protocol, is important in order to improve the prescription of exercises to the population with T2D. Therefore, the objective of this study is to analyze the acute effects at different moments (first and last sessions) of a non-progressive aerobic training program, as well as the chronic effect of this program, on glycemic parameters in patients with T2D. Our hypothesis is that a higher acute glycemic reduction will occur at the beginning of the intervention compared to its end, and that $\mathrm{HbA} 1 \mathrm{c}$ levels will just be maintained after the training period.

\section{Methods}

In this experimental study, one group of individuals was submitted to a physical exercise intervention in which acute and chronic glycemic effects were investigated.

The selection of the individuals occurred through the advertisement of the training program in announcements related to the School of Physical Education, Physiotherapy and Dance (ESEFID) of Universidade Federal do Rio Grande do Sul and in the social media. In addition, individuals were referred by the home care company Hospitalar ATS (city of Porto Alegre, State of Rio Grande do Sul, Brazil), which monitors people with chronic noncommunicable diseases. Adults (individuals older than 18 years) of both sexes with the diagnosis of T2D under follow-up care participated in the research. The following individuals were excluded from the study: individuals with severe autonomic or peripheral neuropathy, foot injuries, severe proliferative or nonproliferative diabetic retinopathy, decompensated heart failure, lower limb amputations, chronic renal failure (glomerular filtration rate estimated by MDRD $\left.<30 \mathrm{ml} / \mathrm{min} / 1.73 \mathrm{~m}^{2}\right)^{12}$, body mass index $(\mathrm{BMI}) \geq 45.0$ $\mathrm{Kg} / \mathrm{m}^{2}$, and individuals with any muscle or joint problems that could negatively affect the safe performance of the walking and/or running activity. All the participants signed a consent document. The study was approved by the Research Ethics Committee of Universidade Federal do Rio Grande do Sul (no. 1.571.144).

After the selection of the sample, the participants were informed about the study's procedures and started a program called pre-training. This program lasted eight weeks and was composed of aerobic exercises (walking/running), without data collection. In the first week of the pre-training stage, each session lasted 20 minutes and consisted of a habitual walking exercise performed continuously. The sessions' duration increased by five minutes each week up to the fourth week, in which they lasted 35 minutes. From the fifth week onwards, the exercise started to be performed in intervals, with the use of Borg's Perceived Exertion $\mathrm{Scale}^{13}$. In this new structure, the participants covered 400 meters between the ratings of perceived exertion (RPE) 11 and 13 and 400 meters between RPE 13 and 15. As the participants performed the interval training over pre-established distances and the RPEs to cover them were indicated, the duration of each block was different within the group. However, the session was always started and finished at the same time for all the participants, ensuring the same duration: 30 and 35 minutes during the fifth and sixth weeks, respectively, and 40 minutes in the seventh and eighth weeks. Every $400 \mathrm{~m}$, the Perceived Exertion Scale was presented to the participants and the desired intensity was indicated. The objective of the pre-training period was to 
make participants become minimally trained, preparing them to the main intervention.

After the pre-training period, blood tests were performed to check HbA1c levels, a maximal exercise test was conducted to determine training intensity, and an anthropometric assessment was carried out to characterize the participants. After these assessments, the aerobic training intervention started, with duration of 16 weeks. In the first and last sessions of the intervention, capillary glucose was assessed before, immediately after and 30 minutes after the session. Between 48 and $72 \mathrm{~h}$ after the last session, a new blood test was performed to determine $\mathrm{HbA1c}$ levels after the training. The full representation of the research, including the intervention and the assessments that were performed, is illustrated in Figure 1.

For the collections of acute glycemic data, before the first and the last training sessions (after 16 weeks of training), each participant remained five minutes at rest to assess the capillary glucose. Then, the aerobic training session was performed. The capillary glucose data were collected immediately after and 30 minutes after the end of the session. After the 16 weeks of intervention, the same collection protocol was carried out. For this collection, we used a glucometer (Accu-Chek Performa, Roche, Portugal) that assesses glycemic levels in approximately five seconds, disposable lancets
(Accu-Chek Performa Roche, Portugal), and test strips.

For the collections of chronic glycemic data, the laboratory-based $\mathrm{HbA} 1 \mathrm{c}$ test was conducted through the method of High Performance Liquid Chromatography (HPLC) before and after the total training period. To perform this test, the participants went to the Endocrimeta laboratory for blood collection after a 12-hour fast.

After the pre-training period, the participants were submitted to an incremental treadmill test to determine the anaerobic threshold heart rate (ATHR), the point based on which the intensity of the proposed training was prescribed. For this test, a treadmill was used (model 10200 ATL, Inbramed, Brazil), adjusted for speed $\left(0.1 \mathrm{~km} / \mathrm{h}^{-1}\right)$ and incline (1\%). Initial speed was $3 \mathrm{~km} / \mathrm{h}$ in the first 3 minutes and it was increased by $1 \mathrm{~km} / \mathrm{h}$ every 2 minutes until the participants' exhaustion. This protocol has already been used in other studies with the same population ${ }^{7,11,14,15}$. Heart rate was monitored by a Polar heart rate monitor (Finland), FT1 model, and registered at every 10 -second interval. ATHR was determined by the heart rate deflection point, which presents a convergent relationship to the second ventilatory threshold in patients with type 2 diabetes $^{15}$.

For the assessment of the anthropometric variables, the participants went to the assessment site on the scheduled day wearing light clothes, adequate to the as-

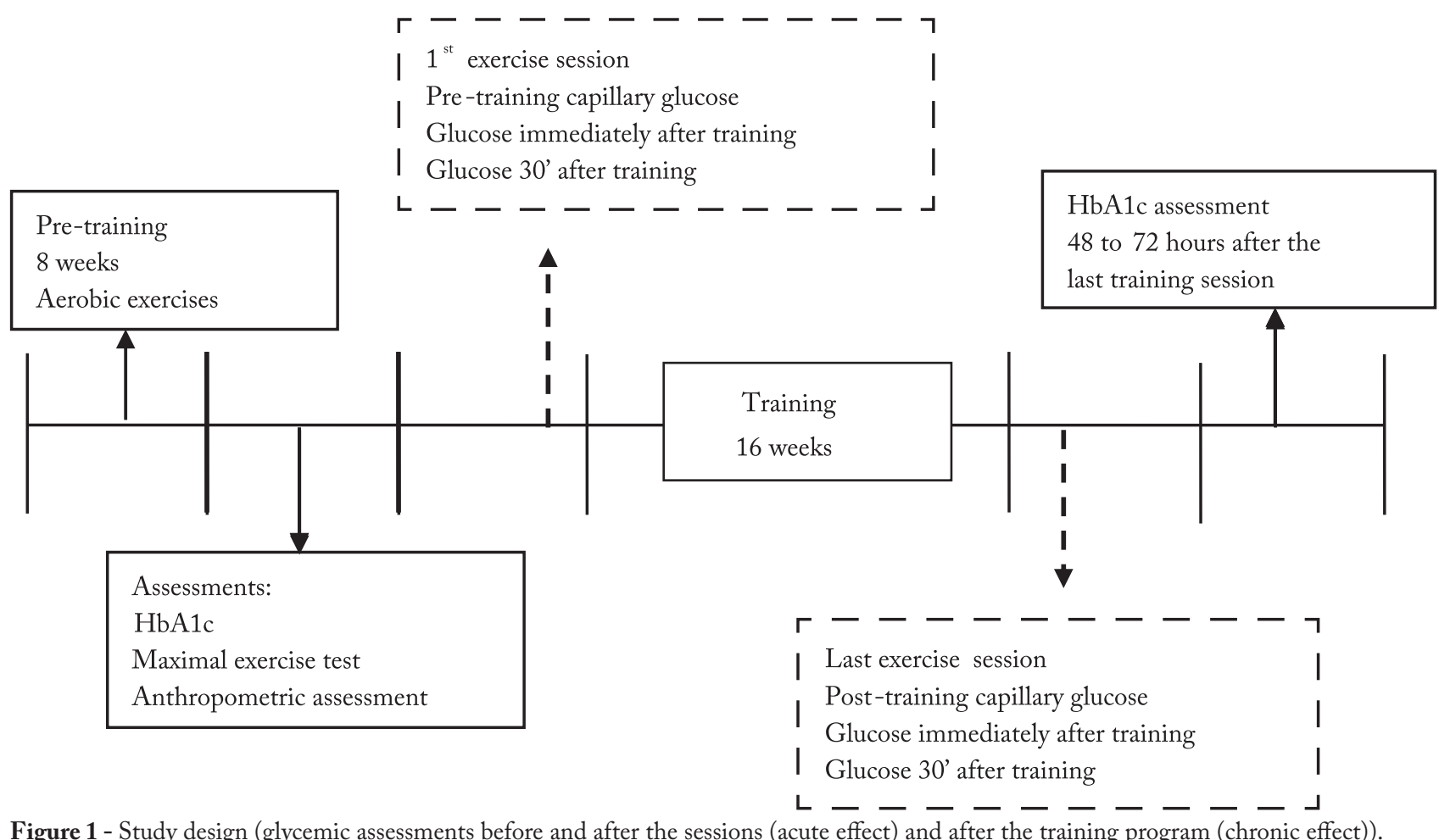


sessment. Initially, stature was measured with a Filizola stadiometer (Brazil), $1 \mathrm{~mm}$ graduation, and body mass was measured with a Filizola mechanical scale (Brazil), with resolution of $0.1 \mathrm{~kg}$. Based on these values, the body mass index (BMI) was calculated, using the formula body mass $(\mathrm{kg}) /$ stature $^{2}(\mathrm{~m})$. Then, waist perimeter was measured with a Cescorf flexible and inelastic tape measure (Brazil), $1 \mathrm{~mm}$ graduation interval, at the midpoint between the last rib and the iliac crest. With this value, the waist/stature ratio was calculated. Finally, seven skinfolds were measured (triceps, subscapular, suprailiac, abdominal, midaxillary, thigh and calf) with a Cescorf caliper (Brazil), which has a $1 \mathrm{~mm}$ graduation interval. Based on these values, body density was estimated, using the appropriate equations for men and women ${ }^{16}$. The body fat percentage of both sexes was also estimated ${ }^{17}$. The value resulting from the sum of the seven skinfolds was considered the sum of the skinfolds.

The intervention was composed of an interval aerobic training of walking and/or running performed on an athletics track during 16 weeks with three weekly sessions. Each session lasted 45 minutes (main part). The interval training consisted of nine blocks of four minutes of stimulus between $85 \%$ and $90 \%$ of the ATHR with active recovery of one minute in an intensity equal to or lower than $85 \%$ of the ATHR. All the participants performed the sessions at the same time and the sessions were supervised by physical education professionals. There was no adjustment of intensity nor progression of the training variables during the 16 weeks.

The sample's characterization data were described as mean and standard deviation for continuous variables (age, anthropometric and glycemic variables) and as absolute frequency " $\mathrm{n}$ " for categorical variables (sex and use of medicines). The Shapiro-Wilk test was used to assess data normality. Glycemic levels (crude data) were described as mean and 95\% confidence interval. They were analyzed by Generalized Estimating Equations, with LSD post-hoc. Due to the small sample size, the observed power of the differences that were found was calculated. To compare glycemic reductions and $\mathrm{HbA} 1 \mathrm{c}$ values between the pre- and post-training moments, the paired t-test was used, with statistical significance $(\alpha)=0.05$. For the analysis of glycemic reductions, two values were adopted: One resulting from the pre-exercise value minus the value immediately after the exercise and the other resulting from the pre-exercise value minus the value 30 minutes after the exercise. The analyses were conducted using the Statistical Package for the Social Sciences (SPSS), version 20.0. To calculate the observed power, we used $G^{*}$ Power 3.1.9.4.

\section{Results}

The sample's characterization data referring to age, sex, anthropometric profile and use of medicines are presented on Table 1 . No hypoglycemic episode nor any other adverse effect occurred during the period of the study.

Table 1 - Characterization of the sample ( $n=7)$, Porto Alegre, 2015.

\begin{tabular}{lc}
\hline Variables & Mean \pm Standard deviation \\
\hline Age (years) & $59.60 \pm 6.69$ \\
Sex (female/male) & $\mathrm{n}=3 / \mathrm{n}=4$ \\
Stature $(\mathrm{m})$ & $1.63 \pm 0.09$ \\
Body mass $(\mathrm{kg})$ & $85.27 \pm 9.79$ \\
BMI $(\mathrm{kg})$ & $31.99 \pm 2.20$ \\
Waist perimeter $(\mathrm{cm})$ & $104.79 \pm 5.0$ \\
WSR & $0.64 \pm 0.04$ \\
\% Fat & $26.13 \pm 6.65$ \\
Fat mass (kg) & $21.87 \pm 4.07$ \\
$\mathbf{\Sigma} 7 \mathrm{SF}$ (mm) & $218.43 \pm 44.82$ \\
Anti-diabetic medication & \\
Metformin & 7 \\
Sulphonylureas & 2 \\
Dipeptidyl peptidase-4 inhibitors & 1 \\
Dapagliflozin & 1 \\
Insulin & 1 \\
\hline
\end{tabular}

$\mathrm{BMI}=$ body mass index; $\mathrm{WSR}=\mathrm{Waist} /$ stature ratio $\boldsymbol{\Sigma} \mathbf{7 S F}=$ sum $^{-}$ mation of 7 skinfolds.

Table 2 presents the data referring to glycemic levels before and after the first and the last training sessions. In the first session, glycemic values immediately after and 30 minutes after the session were lower than the pre-session values. Concerning the last training session, only the glycemic values immediately after the session were lower than the pre-session values, and similar glycemic levels were found between the moments 30 minutes after and before the exercise session.

Analyzing the observed power in the results described, the glycemic reductions found immediately after and 30 minutes after the first training session presented high power ( $98 \%$ and $94 \%$, respectively). As for the glycemic reduction found immediately after the last training session, the observed power was lower (68\%). The observed power was even lower (29\%) for the difference between the glycemic values measured before the exercise in the two sessions. Due to the 
small sample size, the glycemic data were also presented in an individual way (Table 3).

When we analyzed the glycemic reductions (deltas) corresponding to the first and last sessions of the 16 weeks, we found a greater reduction immediately after the exercise $(p=0.042)$ in the first session in comparison to the last training session (first session: -55.14 $\pm 23.63 \mathrm{mg} / \mathrm{dL}$; last session: $-30.29 \pm 29.84 \mathrm{mg} / \mathrm{dL}$ ) - Figure 2, Panel A.

Similarly, the glycemic reduction found $30 \mathrm{~min}-$ utes after the first session was higher $(p=0.027)$ than the glycemic reduction found 30 minutes after the last training session (first session: $-47.14 \pm 29.72 \mathrm{mg} / \mathrm{dL}$; last session: $-16.42 \pm 31.05 \mathrm{mg} / \mathrm{dL}$ ) - Figure 2, Panel B.

Figure 3 presents the $\mathrm{HbA} 1 \mathrm{c}$ levels before and after the 16 weeks of training, which increased from $6.99 \pm 1.17 \%$ to $7.63 \pm 1.26 \%(\mathrm{p}=0.010)$ with the proposed training.

\section{Discussion}

The results about the acute behavior of blood glucose show that the glycemic levels decreased immediately after the first and the last sessions of a 16-week training program and remained below the pre-exercise values 30 minutes after the end of the first session,

Table 2 - Glycemic levels (mg/dL) before, immediately after $\left(0^{\prime}\right)$ and 30 minutes after the first (pre-training) and last (post-training) session of an aerobic training program with 16 weeks' duration $(n=7)$, Porto Alegre, 2015.

\begin{tabular}{llccc}
\hline & $\begin{array}{c}\text { Pre-training } \\
\text { First session }\end{array}$ & $\begin{array}{c}\text { Post-training } \\
\text { Last session }\end{array}$ & p-time & p-session \\
\hline Before the exercise & $172.3(147.3-197.5)$ & $151.1(126.6-175.6) \#$ & & \\
O' after the exercise & $117.2(100.5-134.0)^{*}$ & $120.8(106.2-135.5)^{*}$ & $<0.001$ & 0.664 \\
30' after the exercise & $125.2(107.9-142.6)^{*}$ & $134.7(120.6-148.7)$ & & 0.007 \\
\hline
\end{tabular}

Data described as mean and confidence interval (CI) of $95 \% ;{ }^{*}$ indicates a significant difference in relation to the moment before the exercise in each session (time factor); \# indicates difference between sessions within the same assessment moment (Before the exercise); Comparisons between different moments and/in different sessions were drawn using Generalized Estimating Equations, with LSD post-hoc.

Table 3 - Individual glycemic levels $(\mathrm{mg} / \mathrm{dL})$ before, immediately after $\left(0^{\prime}\right)$ and 30 minutes after the first (pre-training) and last (post-training) session of an aerobic training program with 16 weeks' duration $(\mathrm{n}=7)$, Porto Alegre, 2015.

\begin{tabular}{|c|c|c|c|c|c|c|}
\hline \multirow{2}{*}{ Subjects } & \multicolumn{3}{|c|}{ Pre-training - first session } & \multicolumn{3}{|c|}{ Post-training - last session } \\
\hline & Pre-session & 0 ' after the session & 30 ' after the session & Pre-session & 0 ' after the session & 30 ' after the session \\
\hline 1 & 162 & 96 & 108 & 120 & 93 & 104 \\
\hline 2 & 119 & 103 & 124 & 117 & 116 & 130 \\
\hline 3 & 207 & 127 & 116 & 164 & 155 & 146 \\
\hline 4 & 170 & 93 & 105 & 189 & 121 & 132 \\
\hline 5 & 185 & 133 & 137 & 154 & 102 & 118 \\
\hline 6 & 224 & 161 & 177 & 201 & 141 & 166 \\
\hline 7 & 140 & 108 & 110 & 113 & 118 & 147 \\
\hline
\end{tabular}

A

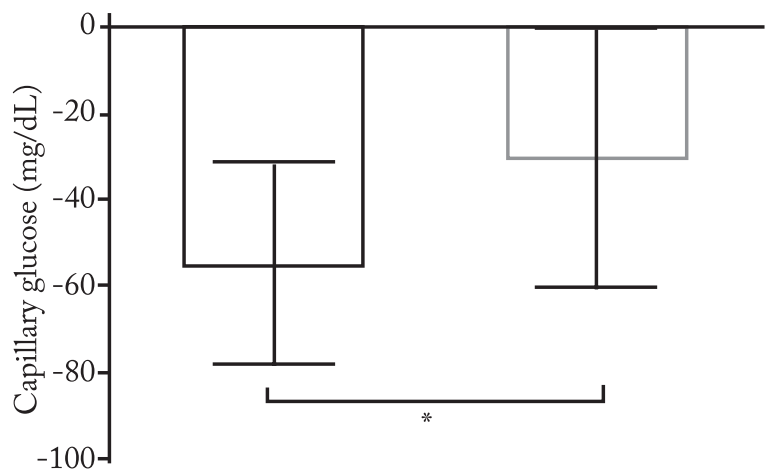

B

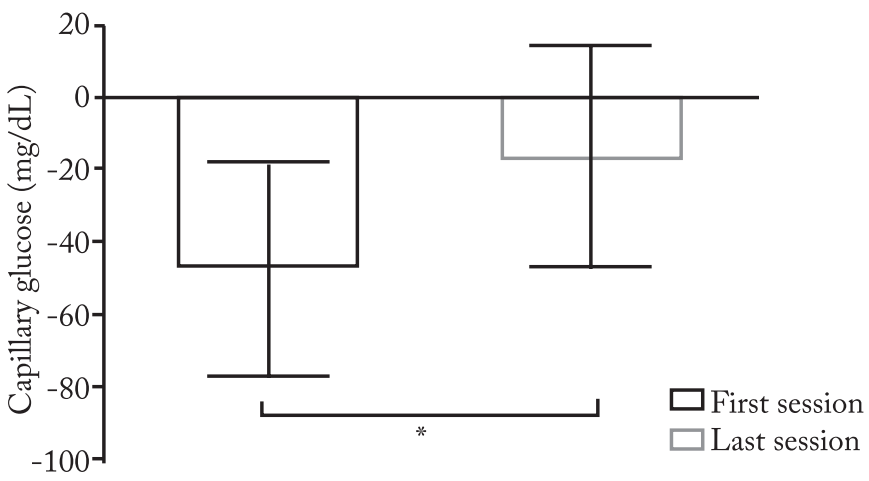

Figure 2 - Glycemic reductions immediately after (Panel A) and 30 minutes after (Panel B) the first (pre-training) and last (post-training) exercise session $(n=7)$, Porto Alegre, 2015.

* indicates a statistically significant difference (Panel A $-p=0.042$; Panel B $-p=0.027)$ between the sessions $(n=7)$. 


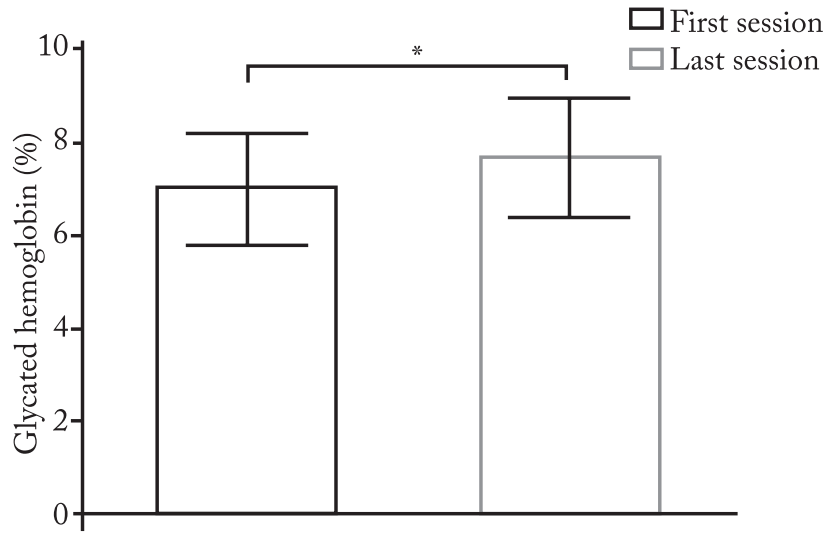

Figura 3 - Glycated hemoglobin (HbA1c) levels before (pre-training) and after the training period (post-training) $(n=7)$, Porto Alegre, 2015.

* indicates a statistically significant difference $(\mathrm{p}=0.010)$ between the moments $(\mathrm{n}=7)$.

a fact that did not occur in the last training session. When we compared the glycemic deltas of the two assessed sessions, we found a significant decrease in the glycemic reduction immediately after and 30 minutes after the last session compared to the first session of the 16 weeks of training, confirming the hypothesis of lower acute glycemic impact at the end of a program of systematic exercises. As for the chronic glycemic result, in spite of a reduction in the pre-exercise session glycemic values, we found an increase in the HbA1c levels after the training period, contradicting our hypothesis that this outcome would not be altered with the intervention model that was carried out.

These findings have clinical relevance because the optimization of glycemic control is a primary objective in the treatment of T2D. Furthermore, in spite of the lower capillary glucose before the last training session, the present prescription of aerobic training with a fixed exercise dose (duration and intensity) throughout 16 weeks was not capable of improving HbA1c levels, a primary outcome in the treatment of the disease. This requires caution in the extrapolation of this intervention model. Visualizing this chronic result synchronically with the acute glycemic impact of the sessions, we perceive that, although the two sessions are capable of reducing blood glucose immediately after the exercise $(-55.14 \pm 23.63 \mathrm{mg} / \mathrm{dL}$ and $-30.29 \pm 29.84$ $\mathrm{mg} / \mathrm{dL}$ in the first and last sessions, respectively), the glycemic reduction 30 minutes after the first session was higher $(-47.14 \pm 29.72 \mathrm{mg} / \mathrm{dL})$ than the one found 30 minutes after the last session $(-16.42 \pm 31.05 \mathrm{mg} /$ $\mathrm{dL}$ ), indicating lower peripheral glucose uptake after the 16 weeks of the same training structure. Howev- er, these comparisons should be drawn with caution, as the initial glycemic values of the last session were lower than the initial values of the first session - the amplitude for acute glycemic reduction at the end of the 16 weeks might have decreased a little. Although it is known that the chronic glycemic effect depends on various factors, like lower systemic inflammation ${ }^{10,18}$, lower sympathetic activation ${ }^{19}$ and lower activity of the renin-angiotensin system ${ }^{20}$, which will lead to less resistance to insulin and, consequently, better glycemic control, the addition of acute glycemic effects seems to promote - or, at least, to be related to - the chronic glycemic effects of the training ${ }^{16}$.

Other studies ${ }^{3,6,8}$ that analyzed the acute effect of aerobic exercise on the blood glucose of patients with T2D have also found glycemic reductions. Figueira et al. ${ }^{6}$ found a glycemic decrease of $27 \mathrm{mg} / \mathrm{dL}$ immediately after a 40-minute session with intensity of $70 \%$ of peak heart rate. Karstoft et al. ${ }^{8}$ assessed acute glycemic effects after a 60-minute session of continuous and interval aerobic training in patients with T2D. After the exercise sessions, they found that the interval exercise had better glycemic control results when compared to the continuous exercise. Santiago et al. ${ }^{3}$ conducted a training protocol similar to the one used in the present study and they also obtained satisfactory results: Glycemic levels were reduced both in the group of continuous training $(45 \mathrm{mg} / \mathrm{dL})$ and in the group of interval training $(49 \mathrm{mg} / \mathrm{dL})$. However, in these studies, the glycemic response to the exercise was assessed within the same moment and/or training status, which makes it difficult to establish a discussion with the proposal of the present study, which focused on the comparison between the glycemic responses at the beginning and at the end of an intervention.

A study conducted by Delevatti et al. ${ }^{14}$, on the other hand, analyzed the acute glycemic response in the first session of three different mesocycles and found the same magnitude of reduction in all the sessions. The authors performed these analyses in sessions conducted in land and water environments and did not find differences between the training environments. It is important to highlight that the sessions of this study were structured in a way that is very similar to that of the present study, with walking and running being prescribed in intervals based on ATHR percentages, but with progression of intensity at every three-week mesocycle. In the present study, the magnitude of reduction was not maintained even with similar structuring and higher duration of the session (45 vs. 35 minutes). 
We believe that the absence of progression of the training variables over a long period (16 weeks) in patients with T2D can explain this difference between findings.

Moving to the chronic glycemic response to training, a consistent meta-analysis ${ }^{21}$ indicated that the structured aerobic training is capable of reducing $\mathrm{HbA} 1 \mathrm{c}$ levels by approximately $0.73 \%$. However, a large clinical trial $^{9}$ in the area did not find reduction in $\mathrm{HbA1}$ c levels after nine months of aerobic training without progression of the training variables. Likewise, Fritz et al. ${ }^{22} \mathrm{did}$ not find reductions in $\mathrm{HbA} 1 \mathrm{c}$ levels after four months of aerobic training (walking) without supervision and without progression of the variables. In the opposite direction, Delevatti et al. ${ }^{14}$ found a $0.39 \%$ reduction in $\mathrm{HbA} 1 \mathrm{c}$ levels after 12 weeks of aerobic training (walking and/or running) with progression of $85 \%$ to $100 \%$ of the ATHR during the intervention. While some studies without training progression did not find improvements and one study ${ }^{14}$ whose initial structure was very similar to the present one, but with progression, found benefits, in the present study, the HbA1c levels worsened. Although this result was not expected, we believe that the previous trainability provided by the pre-training period, as well as the non-progression of the training over a long period, associated with lack of rigid control of intervening variables like eating habits, can explain the result that was found.

Analyzing the findings related to acute and chronic responses in a joint way, it is possible to suggest that the lack of progression of the training variables may be related to the decrease in the magnitude of the acute glycemic reduction and may represent a methodological limitation of aerobic trainings that focus on the glycemic control of patients with T2D.

The study has some limitations, such as sample size, which can be considered small; the absence of a group without structured exercise, that is, a control group; and lack of progression of the training variables or of adjustment of intensity, as the proposed intensity for each individual might have become underestimated at a certain moment and trainability status. Another limitation is the lack of control of the participants' eating habits, as what they ate may have influenced the difference that was found between glucose concentrations before the exercise at the beginning and at the end of the 16 weeks. However, the study aimed to analyze acute glycemic effects at different moments of an aerobic training program, as well as the chronic effect of the same program, which makes it be distinct from a large part of the studies that have also analyzed acute glycemic effects, but within the same training status. Moreover, the training program was conducted in a controlled way, with monitoring of the training variables and individualized prescription of intensity.

Based on the results that were found, it is possible to conclude that, despite the broad prescription of aerobic training as a therapeutic practice in T2D, progression of the training variables seems to be important to sustain the acute glycemic responses over time and to promote beneficial chronic responses, as, in a period of 16 weeks, the acute glycemic impact was reduced and the chronic glycemic results were not satisfactory with the aerobic training proposed in the present study.

Further studies must investigate acute and chronic glycemic effects in larger samples, with greater control of the intervening variables, and comparisons between models with and without training progression. Such investigations can provide, for exercise professionals who work with this public, a more complete view of the adequate training prescription for the glycemic control of patients with T2D.

\section{Conflicts of interest}

The authors declare there are no conflicts of interest.

\section{Authors' contribution}

Delevatti RS, participated in the initial conception of the study, data collection, bibliographic search, and in the writing of the manuscript. Netto N, participated in the initial conception of the study, data collection, data analysis, bibliographic search, and in the writing of the manuscript. Heberle I participated in data analysis, bibliographic search, and in the writing of the manuscript. Bracht CG, Santiago E and Lisboa SDC, participated in data collection and in the writing and critical review of the manuscript. Costa RR, participated in data analysis and in the writing and critical review of the manuscript. Hübner A, Fossati $M$ and Kruel LFM, participated in the initial conception of the study and in the critical review of the manuscript.

\section{Acknowledgements}

The authors thank CAPES, CNPq and Hospitalar ATS, as well as all the study's participants.

\section{References}

1. American Diabetes Association. Standards of Medical Care in Diabetes-2018. Diabetes Care. 41oed 2018;1-159.

2. Yang Z, Scott CA, Mao C, Tang J, Farmer AJ. Resistance exercise versus aerobic exercise for type 2 diabetes: a systematic review and meta-analysis. Sports Med. 2014;44(4):487-99. 
3. Santiago É, Delevatti RS, Bracht CG, Netto N, Lisboa SC, Vieira AF, et al. Acute glycemic and pressure responses of continuous and interval aerobic exercise in patients with type 2 diabetes. Clin Exp Hypertens. 2018;40(2):179-85.

4. Terada T, Friesen A, Chahal BS, Bell GJ, McCargar LJ, Boulé NG. Exploring the Variability in Acute Glycemic Responses to Exercise in Type 2 Diabetes. J Diabetes Res.2013;2013:1-6.

5. Bacchi E, Negri C, Trombetta M, Zanolin ME, Lanza M, Bonora $\mathrm{E}$, et al. Differences in the acute effects of aerobic and resistance exercise in subjects with type 2 diabetes: Results from the RAED2 Randomized Trial. PLoS ONE. 2012;7(12):e49937.

6. Figueira FR, Umpierre D, Casali KR, Tetelbom PS, Henn NT, Ribeiro JP, et al. Aerobic and combined exercise sessions reduce glucose variability in type 2 diabetes: crossover randomized trial. PLoS ONE. 2013;8(3):e57733.

7. Delevatti RS, Pinho CDF, Marson EC, Bregagnol LP, Lisboa $\mathrm{SC}$, Kruel LFM. Acute glycemic outcomes along the aerobic training in deep water in patients with type 2 diabetes. Arch Med Deporte. 2016;33(4):233-38.

8. Karstoft K, Christensen CS, Pedersen BK, Solomon TPJ. The Acute Effects of interval- vs continuous-walking exercise on glycemic control in subjects with type 2 diabetes: A crossover, controlled study. J Clin Endocr Metab. 2014;99(9):3334-42.

9. Church TS, Blair SN, Cocreham S, Johannsen N, Johnson W, Kramer K, et al. Effects of aerobic and resistance training on hemoglobin a1c levels in patients with type 2 diabetes: A randomized controlled trial. JAMA. 2010;304(20):2253.

10. Jorge MLMP, Oliveira VN, Resende NM, Paraiso LF, Calixto A, Diniz ALD, et al. The effects of aerobic, resistance, and combined exercise on metabolic control, inflammatory markers, adipocytokines, and muscle insulin signaling in patients with type 2 diabetes mellitus. Metabolism. 2011;60(9):1244-52.

11. Delevatti RS, Kanitz AC, Alberton CL, Marson EC, Lisboa SC, Pinho CDF, et al. Glucose control can be similarly improved after aquatic or dry-land aerobic training in patients with type 2 diabetes: A randomized clinical trial. J Sci Med Sport. 2016;19(8):688-93.

12. O'Meara E, Chong KS, Gardner RS, Jardine AG, Neilly JB, Mc Donagh TA. The Modification of Diet in Renal Disease (MDRD) equations provide valid estimations of glomerular filtration rates in patients with advanced heart failure. Eur J Heart Fail. 2006;8(1):63-7.
13. Borg G. Borg's Perceived Exertion And Pain Scales. Champaign: Human Kinetics, 1998.

14. Delevatti RS, Pinho CDF, Kanitz AC, Alberton CL, Marson EC, Bregagnol LP, et al. Glycemic reductions following water- and land-based exercise in patients with type 2 diabetes mellitus. Complement Ther Clin Pract. 2016;24:73-7.

15. Delevatti RS, Kanitz AC, Alberton CL, Pantoja PD, Marson EC, Pinho CDF, et al. Heart rate deflection point as an alternative method to identify the anaerobic threshold in patients with type 2 diabetes. Apunts Med. Sport. 2015;50(188):123-8.

16. Duclos M, Virally M-L, Dejager S. Exercise in the Management of Type 2 Diabetes Mellitus: What are the Benefits and how does it Work? The Phys Sports med. 2011;39(2):98-106.

17. HeywardVH ,Stolarczyz LM. Avaliação da composição corporal aplicada. São Paulo: Manole, 2001.

18. Kadoglou NPE, Fotiadis G, Kapelouzou A, Kostakis A, Liapis CD, Vrabas IS. The differential anti-inflammatory effects of exercise modalities and their association with early carotid atherosclerosis progression in patients with Type 2 diabetes. Diabetic Med. 2013;30(2):e41-50.

19. Castro AVB, Kolka CM, Kim SP, Bergman RN. Obesity, insulin resistance and comorbidities? Mechanisms of association. Arq Bras Endocrinol. 2014;58(6):600-9.

20. Carvalho-Filho MA, Carvalheira JBC, Velloso LA, Saad MJA. Cross-talk das vias de sinalização de insulina e angiotensina II: implicações com a associação entre diabetes mellitus e hipertensão arterial e doença cardiovascular. Arq Bras Endocrinol. 2007;51(2):195-203.

21. Umpierre D. Physical activity advice only or structured exercise training and association with $\mathrm{HbA} 1 \mathrm{c}$ levels in type 2 diabetes: a systematic review and meta-analysis. JAMA. 2011;305(17):1790.

22. Fritz T, Wändell P, Åberg H, Engfeldt P. Walking for exercise-does three times per week influence risk factors in type 2 diabetes? Diabetes Res Clin pr. 2006;71(1):21-7.

Received: $15 / 12 / 2018$

Approved: 24/05/2019

Quote this article as:

Delevatti RS, Netto N, Heberle I, Bracht CG, Santiago E, Lisboa, SDC, et al. Acute and chronic glycemic effects of aerobic training in patients with type 2 diabetes. Rev Bras Ativ Fis Saúde. 2018;23:e0063. DOI: 10.12820/rbafs.23e0063 